Document downloaded from:

http://hdl.handle.net/10251/45168

This paper must be cited as:

Catalá, M.; Gasulla Vidal, F.; Pradas Del Real, A.; García Breijo, FJ.; Reig Armiñana, J.; Barreno Rodriguez, E. (2013). The organic air pollutant cumene hydroperoxide interferes with NOantioxidant role in rehydrating lichen. Environmental Pollution. 179:277-284. doi:10.1016/j.envpol.2013.04.015.

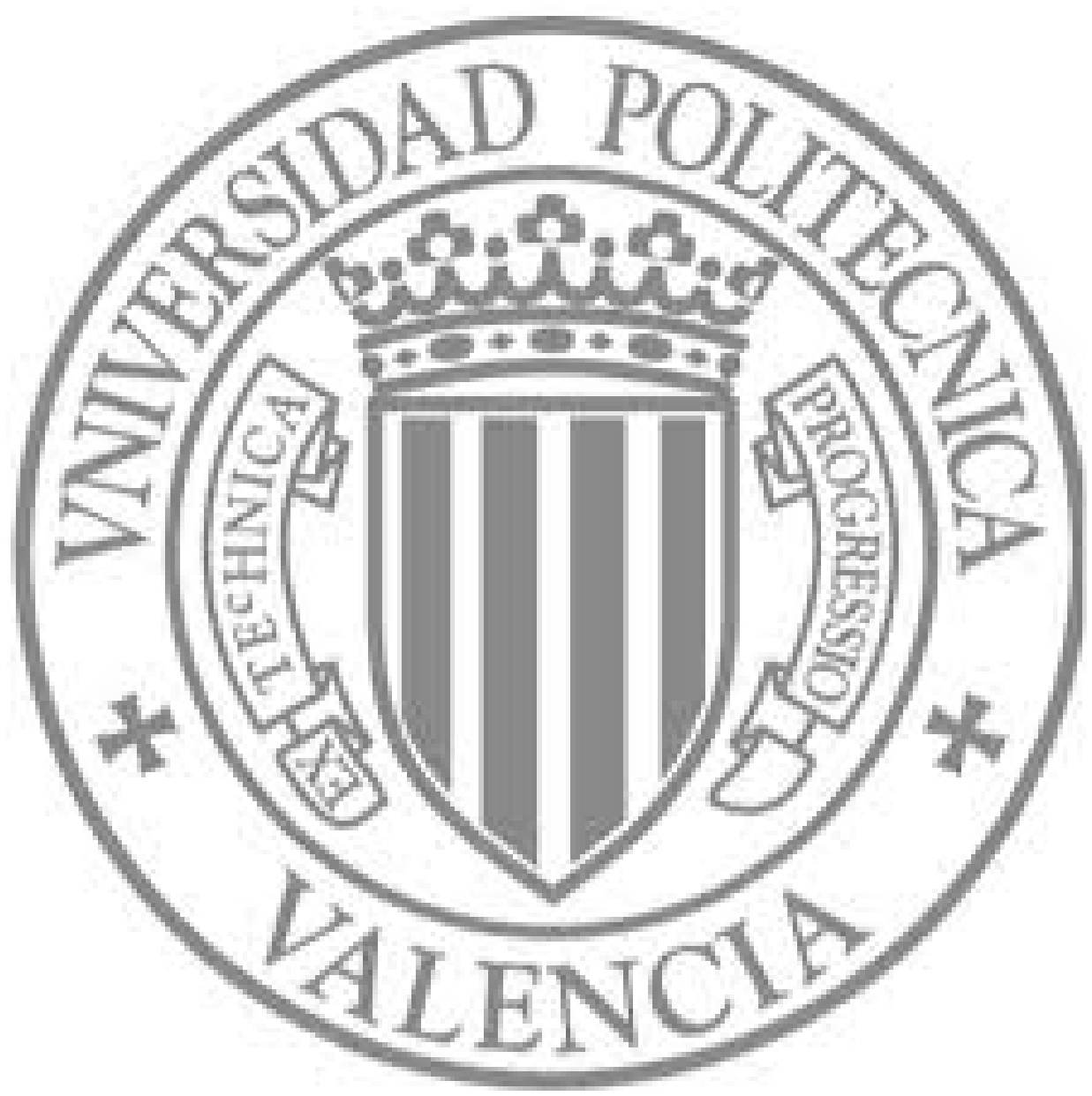

The final publication is available at

http://dx.doi.org/10.1016/j.envpol.2013.04.015

Copyright Elsevier 


\title{
The organic air pollutant cumene hydroperoxide interferes with NO antioxidant role in rehydrating lichen
}

\author{
M. Cataláa,*, F. Gasulla ${ }^{\text {b }}$, A.E. Pradas del Real ${ }^{c}$, F. García-Breijo ${ }^{\text {b,d }}$, J. Reig-Armiñana ${ }^{\text {, }}$ \\ E. Barreno ${ }^{b}$ \\ a Universidad Rey Juan Carlos, Biología Celular, Dept Biología y Geología, (ESCET), Dptal 1, 241, ESCET - Campus de Móstoles, c/Tulipán s/n, \\ E-28933 Móstoles, Madrid, Spain \\ ${ }^{\mathrm{b}}$ Universitat de València, ICBIBE, Jardí Botànic, Fac. C. Biológicas, 46100 Burjassot, Valencia, Spain \\ ' IMIDRA, Dept Investigación Agroambiental, Madrid, Spain \\ ${ }^{\mathrm{d}}$ Universitat Politécnica de Valencia, Dept Ecosistemas Agroforestales, Valencia, Spain
}

\begin{abstract}
A B S T R A C T
Organic pollutants effects on lichens have not been addressed. Rehydration is critical for lichens, a burst of free radicals involving NO occurs. Repeated dehydrations with organic pollutants could increase oxidative damage. Our aim is to learn the effects of cumene hydroperoxide (CP) during lichen rehydration using Ramalina farinacea (L.) Ach., its photobiont Trebouxia spp. and Asterochloris erici. Confocal imaging shows intracellular ROS and NO production within myco and phycobionts, being the chloroplast the main source of free radicals. CP increases ROS, NO and lipid peroxidation and reduces chlorophyll autofluorescence, although photosynthesis remains unaffected. Concomitant NO inhibition provokes a generalized increase of ROS and a decrease in photosynthesis. Our results suggest that CP induces a compensatory hormetic response in Ramalina farinacea that could reduce the lichen's antioxidant resources after repeated desiccation-rehydration cycles. NO is important in the protection from $\mathrm{CP}$.
\end{abstract}

\section{Introduction}

A lichen is a symbiotic association of a fungus (mycobiont) and a photosynthetic partner (photobiont), that may be an alga or cyanobacterium. The association is not a simple mixture though; the fungus produces a thallus or body, where the photobiont is housed. A predominant characteristic of lichens is their ability to survive anhydrobiosis, a state of suspended animation in which "desiccation tolerant" organisms survive indefinite periods until rehydration allows them to resume metabolism.

Lichens can be considered as ecosystems themselves where the interaction of partners results in behaviour and life forms that are not found in the isolated partners (Oksanen, 2006), allowing them to live in habitats previously unavailable (Kranner et al., 2008; Kranner and Birtic, 2005). They survive in extreme environments and have been demonstrated to be the organisms able to survive longer periods in outer space (Horneck et al., 2010). However, air pollution impairs lichen colonization and survival (Barreno, 2002). $\mathrm{SO}_{2}, \mathrm{O}_{3}$ and $\mathrm{NO}_{x}$ have been related with lichen damage but the

\footnotetext{
* Corresponding author.

E-mail addresses: myriam.catala@urjc.es, mcr4370@gmail.com (M. Catalá).
}

toxicity mechanisms overwhelming their extraordinary abiotic stress defence system have not been fully elucidated (Riddell et al., 2012, 2008; Hauck et al., 2008; Tretiach et al., 2007; Kong et al., 1999; Bačkor and Fahselt, 2003; Kong et al., 2002).

Desiccation-rehydration cycles are natural for lichens. Rehydration is a critical phase of lichen life cycle since a burst of free radicals occurs, both extracellular and intracellular (Kranner et al., 2008; Catalá et al., 2010b; Weissman et al., 2005). An alteration in the lichen pro-oxidant/anti-oxidant balance during repeated desiccation-rehydration cycles might cause important cell damage such as lipid and protein peroxidation, chlorophyll photooxidation or DNA damage. Lichens possess important antioxidant systems and a strong relation of glutathione with desiccation tolerance has been demonstrated (Kranner, 2002). However, this relation has not been found for other classical mechanisms and the role of nonclassical still remains to be elucidated (Gasulla et al., 2009). As a matter of fact, the lichen cell biology and the physiology of symbiosis remain mostly undeciphered. This lack of knowledge prevents, to a great extent, the development of efficient programmes for lichen biodiversity protection or a putative biotechnological exploitation of lichen biological peculiarities.

Lichens have no roots and depend mainly on the atmospheric input of mineral nutrients. With no other protection barrier, such as 
the waxy cuticle that has evolved in vascular plants, the lichen thallus is susceptible to the penetration of airborne substances, some of which are essential for cell function, while others may be toxic. They are excellent passive samplers of environmental pollution both for inorganic and organic compounds (Wannaz et al., 2012; Nash and Gries, 2002, 1995; Augusto et al., 2010). These features of lichens, combined with their extraordinary capability to grow in a large geographical range and accumulate mineral elements far above their needs, rank them among the best bioindicators (Garty et al., 2003). The ability of lichens to tolerate and even bioaccumulate heavy metals such as $\mathrm{As}, \mathrm{Pb}$ or $\mathrm{Cd}$, has been extensively studied (Bajpai and Upreti, 2012; State et al., 2012; Bačkor et al., 2011; Pawlik-Skowronska and Bačkor, 2011; Bačkor et al., 2010) as well as the noxious effects of inorganic pollutants such as $\mathrm{O}_{3}, \mathrm{SO}_{2}$ or $\mathrm{NO}_{x}$ (Riddell et al., 2012; Hauck et al., 2008; Tretiach et al., 2007; Hauck, 2010). However, the toxic effects of volatile organic pollutants (VOPs) on lichens have not been addressed yet.

It is long known that the combination of emitted pollutants (i.e. cumene or [1-methylethyl] benzene) and solar photo-oxidations cause the existence of significant levels of pro-oxidative air pollutants (i.e. cumene hydroperoxide, $\mathrm{CP}$ ) which are uptaken by biota through dry or wet deposition, even at distant points from the emission source (Tice and Brevard, 1998 and references therein). Cumene hydroperoxide may enter the environment from industrial discharges and spills, and also as a by-product of fuel oil slicks exposed to UV light (Callen and Larson, 1978; Victorin and Stahlberg, 1988). This substance is cytotoxic, genotoxic and mutagenic, inducing DNA damage and mutations in prokaryote and eukaryote systems. CP has been frequently used as a model for the biological effects of the alkyl hydroperoxides derived from VOPs (Kumar et al., 2012; Sen et al., 2012; Haslekås et al., 2003; Catalá et al., 2010a). Its mechanism involves homolytic cleavage of the peroxide $\mathrm{O}-\mathrm{O}$ bond by cytochromes $\mathrm{P}_{450}$ to produce the cumoxyl radical (Barr et al., 1996). The effects are enhanced by metals and inhibited by free radical scavengers such as ascorbate (Tsai et al., 1997; Timmins and Davies, 1993).

The multifaceted nitric oxide (NO) has multiple biological functions in a very broad range of organisms. Not long ago NO was regarded by plant biologists as an environmental pollutant causing damage to plants. However, the advances in the last years have demonstrated that endogenous modulated levels of $\mathrm{NO}$ are involved in signal transduction, cell death, nutrient transport, basic metabolism, ROS production and degradation among others (reviewed in Siddiqui et al., 2011). In plants, ROS and reactive nitrogen species have been shown to be involved in the defensive response of plants to biotic or abiotic stresses (drought, salinity, extreme temperatures, xenobiotics, air pollutants or UV-B radiation). In the late 70s NO radical was shown to protect crop leaves from pesticides by acting as free radical scavenger (reviewed in Corpas et al., 2006). Protection against heavy metals, ethylene and herbicides through elevation of antioxidant activities was later documented. A role of NO in plant-pathogen cross-talk including the triggering of programmed cell death or resistance has also been reported in several models (reviewed in Arasimowicz and Floryszak-Wieczorek, 2007). However, nitric oxide dysregulation and imbalance can also provoke a nitrosative response leading to cell damage (reviewed in Corpas et al., 2011).

We have recently demonstrated that NO plays an important role in the regulation of lichen oxidative stress during the critical first minutes of rehydration (Catalá et al., 2010b). Our results suggest that mycobiont-related NO helps stabilize phycobiont photosystem II. Since NO inhibition induces alterations in isolated phycobionts but not in whole lichens, a role in the establishment of lichen symbiosis is suggested, as hypothesized by Feelisch and Martin (1995) and confirmed for mycorhizal and rhizobium models (Bonfante and Requena, 2011; Meilhoc et al., 2011; Hérouart et al., 2002). We have also reported that the inhibition of NO in the lichen Ramalina farinacea during CP treatment increases intracellular mycobiont-associated ROS release but helps restore lipid peroxidation to physiological values (Catalá et al., 2010a). Organic pollutants are most likely involved together with inorganic gases in lichen biodiversity decay. Therefore, repeated rehydration cycles in the presence of prooxidant atmospheric organic pollutants could increase free radical release, especially during algal chlorophyll reconstitution, and activate mycobiont derived NO release as antioxidant. The aim of this work is to gain insight into the effects of the volatile organic pollutant cumene hydroperoxide on oxidative stress and photosynthesis during lichen rehydration oxidative burst and the role of NO during this process using the lichen Ramalina farinacea and Asterochloris erici as biological models.

\section{Material and methods}

\subsection{Chemicals}

The chemicals 2,6-di-tert-buthyl-4-methylphenol trichloroacetic acid (BHT), 2thiobarbituric acid (TBA), 1,1,3,3,tetraethoxypropane (TEP), cumene hydroperoxide 88\% (CP), and bisbenzimide $\mathrm{H}$ (Hoechst) were provided by Sigma Aldrich Química S.A (Tres Cantos, Spain); 2,7-dichlorodihydrofluorescein diacetate ( $\left.\mathrm{DCFH}_{2}-\mathrm{DA}\right)$, hydrochloric acid $(\mathrm{HCl})$ and ethanol (etOH) were purchased from Panreac Química S.A.U (Barcelona, Spain); 2-(4-carboxyphenyl)-4,4,5,5-tetramethylimidazoline-1oxyl-3-oxide potassium salt (cPTIO) and 2,3-diaminonaphthalene (DAN) were from Invitrogen S.A (El Prat de Llobregat, Spain); and Triton X-100 was from VWR Prolabo (Barcelona, Spain).

\subsection{Lichen material}

Ramalina farinacea (L.) Ach. was collected in the air-dried state from Quercus rotundifolia Lam. at Sierra de El Toro (Castellón, Spain; 39 $54^{\prime} 16^{\prime \prime} \mathrm{N}, 0^{\circ} 48^{\prime} 22^{\prime \prime} \mathrm{W}$ ). Samples were maintained in a silica gel atmosphere during $24 \mathrm{~h}$ and frozen at $-20^{\circ} \mathrm{C}$ until the experiment, 1 month after collection.

\subsection{Epifluorescence probes}

2,7-Dichlorodihydrofluorescein diacetate $\left(\mathrm{DCFH}_{2}-\mathrm{DA}\right)$ was used as probe in the detection of free radicals (Wardman, 2007) (DCF, $\lambda_{\mathrm{exc}}=504 \mathrm{~nm}, \lambda_{\mathrm{em}}=524 \mathrm{~nm}$, green). $\mathrm{DCFH}_{2}$-DA is not appreciably oxidized to the fluorescent state without prior hydrolysis inside the cell. 2,3-Diaminonaphthalene (DAN) reacts with the nitrosonium cation that forms spontaneously from NO to yield the fluorescent product $1 \mathrm{H}$-naphthotriazole which emits blue fluorescence $\left(\lambda_{\mathrm{exc}}=375 \mathrm{~nm}, \lambda_{\mathrm{em}}=425 \mathrm{~nm}\right.$ ) Since the selectivity of DAN for the nitrosonium cation is high, NO can be detected without the inhibition of its function (Kojima et al., 1997).

In order to maintain real fluorescence colours in the confocal images, green has been assigned to DCF emission and red to chlorophyll autofluorescence using the software OLYMPUS FLUOVIEW Viewer Ver. 2.1.c. Since the contrast of blue colour on black is difficult to perceive, a complex gamma based on blue (Spec 3 ) has been used for DAN fluorescence. No significant green autofluorescence and only punctual blue fluorescence, related with debris, was observed in the absence of the probes.

\subsection{Fluorometric kinetics of free radical production and chlorophyll autofluorescence}

Dry fragments of lichen thalli were placed in black flat bottom 96 multiwel plates and kept at $-20^{\circ} \mathrm{C}$ until use. One of the plates was thawed and rehydrated with deionized water $24 \mathrm{~h}$ before the experiment and kept at $17{ }^{\circ} \mathrm{C}$, PAR $35 \mu \mathrm{mol} \mathrm{m}{ }^{-2} \mathrm{~s}^{-1} 16 / 8 \mathrm{~h}$ photoperiod. The second plate was thawed immediately before the experiment.

Both dry and hydrated lichens were submerged during $5 \mathrm{~min}$ in deionized water $10 \mu \mathrm{M} \mathrm{DCFH}{ }_{2}$-DA with or without c-PTIO $200 \mu \mathrm{M}$. The excess of solution was eliminated and the kinetics of DCF and chlorophyll emitted fluorescence were simultaneously measured in a SPECTRAFluor Plus microplate reader (Tecan Group Ltd., Männedorf, Switzerland). Excitation of both substances was performed at $\lambda_{\text {exc }}$ $485 \mathrm{~nm}$, emission of DCF fluorescence was recorded at $\lambda_{\mathrm{em}} 535 \mathrm{~nm}$ and chlorophyll autofluorescence at $\lambda_{\mathrm{em}} 635 \mathrm{~nm}$, during one hour. Twelve replicates were analysed by treatment and all values are referred to the weight of sample.

\subsection{Microscopy}

Fragments of lichen thalli were rehydrated for 5 min with $10 \mu \mathrm{M} \mathrm{CP}$ with or without $200 \mu \mathrm{M}$ c-PTIO, and the fluorescence probes ( $10 \mu \mathrm{M} \mathrm{DCFH}$-DA and $200 \mu \mathrm{M}$ DAN). They were incubated at room temperature and dimmed light for at least $4 \mathrm{~h}$. The samples were then placed in a freezing microtome (CM 1325; Leica, Germany) and cut in sections of 30 microns. The slices were washed with deionized water and 
mounted on slides prior to their observation by fluorescence microscopy (OLYMPUS Provis AX 70 fluorescence microscope) or confocal laser scanning microscopy (OLYMPUS FV 1000) at the UCIM (University of Valencia). Fluorescence was excited using a $405 \mathrm{~nm}$ diode laser, an argon laser (488 nm) and a $635 \mathrm{~nm}$ diode laser and measured sequentially in three channels: $425-475 \mathrm{~nm}$ (chan. 1), 500-600 nm (chan. 2) and 655-755 $\mathrm{nm}$ (chan. 3).

\subsection{Isolated photobionts of Ramalina farinacea}

The photobionts of $R$. farinacea (Trebouxia spp.) were isolated following the protocol described by Gasulla et al. (2010). Algae were grown in 3N Bold's basa medium (BBM3N) containing $10 \mathrm{~g}$ casein and $20 \mathrm{~g}$ glucose per litre (Bačkor and Váczi, 2002 ) with a $16: 8 \mathrm{~h}$ light:dark photoperiod and at a temperature of $15^{\circ} \mathrm{C}$. The medium was changed every 2 weeks and the concentration of algae set at $10^{5}$ cells $/ \mathrm{ml}$

\subsection{Physiology of photosynthesis}

An axenic strain of the lichen photobiont Asterochloris erici (Ahmadjian) Skaloud et Peksa (SAG $32.85=$ UTEX 911) was used for this study. Algae were grown on cellulose-acetate discs on agar BBM3N containing $10 \mathrm{~g}$ casein and $20 \mathrm{~g}$ glucose per litre (Bačkor and Váczi, 2002; Goldsmith et al., 1997). Cultures were maintained at $20{ }^{\circ} \mathrm{C}$ under a $12 \mathrm{~h}$ photoperiod with $30 \mu \mathrm{mol} \mathrm{m} \mathrm{m}^{-2} \mathrm{~s}^{-1}$ white-light illumination.

After 21 days, the discs were removed from the culture medium and dried into Petri plates with silicagel (RH 20\%). The samples remained dried for $24 \mathrm{~h}$ and were then rehydrated with distilled water, cumene hydroperoxide (CP) $10 \mu \mathrm{M}$, c-PTIO $200 \mu \mathrm{M}$, or CP plus c-PTIO. Samples were returned to the agar culture media and maintained in culture conditions during $24 \mathrm{~h}$

In vivo chlorophyll $a$ fluorescence was measured with a modulated light fluorometer (PAM-2000, Walz, Effeltrich, Germany). The samples were kept in the dark for $30 \mathrm{~min}$ and the minimum (dark) fluorescence yield $\left(F_{0}\right)$ measured after excitation of the algae with a weak measuring beam from a light-emitting diode. The maximum fluorescence yield $\left(F_{\mathrm{m}}\right)$ was determined with an $800 \mathrm{~ms}$ saturating pulse of white light (SP, $\left.8000 \mu \mathrm{mol} \mathrm{m} \mathrm{m}^{-2} \mathrm{~s}^{-1}\right)$. Variable fluorescence $\left(F_{\mathrm{v}}\right)$ was calculated as $F_{\mathrm{m}}-F_{\mathrm{o}}$, and the maximum quantum yield of photosystem II (PSII) as $F_{\mathrm{v}} / F_{\mathrm{m}}$. The samples were allowed to re-adapt in the dark for $2 \mathrm{~min}$, after which actinic light (AL, $200 \mu \mathrm{mol} \mathrm{m} \mathrm{m}^{-2} \mathrm{~s}^{-1}$ ) was switched on, and SPs were applied at $1 \mathrm{~min}$ intervals to determine: (1) the maximum fluorescence yield during actinic illumination $\left(F_{\mathrm{m}}^{\prime}\right),(2)$ the level of modulated fluorescence during a brief $(3 \mathrm{~s})$ interruption of actinic illumination in the presence of $6 \mu \mathrm{mol} \mathrm{m} \mathrm{m}^{-2} \mathrm{~s}^{-1}$ far red (FR, $730 \mathrm{~nm}$ ) light $\left(F^{\prime}{ }_{\mathrm{o}}\right)$, and (3) steady-state chlorophyll $a$ fluorescence yield after 11 pulses $\left(F_{\mathrm{s}}\right)$. Photochemical quenching $\left(q_{\mathrm{P}}\right)$, and the quantum efficiency of PSII photochemistry ( $\left.\Phi_{\mathrm{PSII}}\right)$ were estimated following the methods of Genty et al. (1989) and Kramer et al. (2004).

\subsection{Measurement of malondialdehyde}

Lipid peroxidation was evaluated in $R$. farinacea thalli and phycobionts as thiobarbituric acid reactive substances (TBARS) by the method of Reilly and Aust (1999), modified as described below (Botsoglou et al., 1994; Du and Bramlage, 1992). Working standards were made by diluting a $2 \mathrm{mM}$ stock solution of the malondialdehyde precursor TEP with $80 \%$ ethanol supplemented with $2 \%$ of the antioxidant BHT to suppress the decomposition of lipid peroxides during the assay. Working concentrations of $0-50 \mu \mathrm{M}$ were prepared.

Fragments of lichen thalli were rehydrated for $5 \mathrm{~min}$ with deionized water for controls, $10 \mu \mathrm{M} \mathrm{CP}$ and $10 \mu \mathrm{M}$ CP plus $200 \mu \mathrm{M}$ c-PTIO. Excess liquid was wiped off and

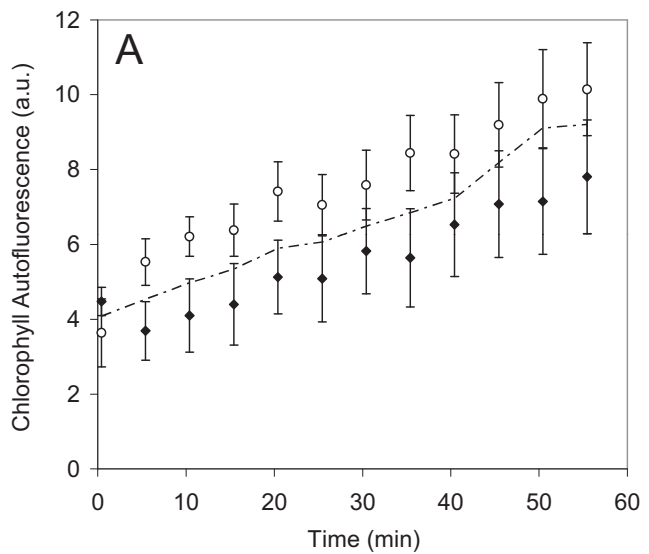

the thalli were then incubated under growing conditions in Petri dishes for 0,1, 2, 4 or $24 \mathrm{~h}$ and frozen at $-20^{\circ} \mathrm{C}$. For analysis, thalli were thawed, weighed and homogenized on ice with deionized water $(50 \mathrm{mg} / \mathrm{ml})$ and centrifuged at $16,060 \times g$ for $10 \mathrm{~min}$. Supernatants were frozen at $-20{ }^{\circ} \mathrm{C}$ for $\mathrm{NO}_{x}$ analysis, and the pellets resuspended in $500 \mu \mathrm{l}$ ethanol-BHT. Ramalina farinacea isolated phycobionts were incubated in $10 \mu \mathrm{M}$ $\mathrm{CP}$ and $10 \mu \mathrm{M}$ CP plus $200 \mu \mathrm{M}$ c-PTIO and subsequently homogenized directly in $500 \mu \mathrm{l}$ of ethanol-BHT with glass fragments (approx. $1 \mathrm{~mm}$ diameter) and strong vortexing for $30 \mathrm{~min}$. Subsequently, $900 \mu \mathrm{M}$ of TBA $\left(2.57 \times 10^{-2} \mathrm{M}\right)$, TCA $\left(9.18 \times 10^{-1} \mathrm{M}\right)$, and $\mathrm{HCl}$ $(3.20 \mathrm{M})$ working solution was added to each sample and to the standards. The samples and standards were vortexed in a Vortex Labnet $\times 100$ for $5 \mathrm{~min}$ at $3000 \mathrm{rpm}$ and then placed in a $70^{\circ} \mathrm{C}$ water bath for $30 \mathrm{~min}$. Afterwards, the samples and standards were vortexed again, cooled on ice, and centrifuged at 10,060 $\times \mathrm{g}$ for $10 \mathrm{~min}$.

The absorbance of supernatants was measured at $532 \mathrm{~nm}\left(A_{532}\right)$ in a Spectronic Genesys 8 spectrophotometer. The absorbance at $600 \mathrm{~nm}\left(A_{600}\right)$ was then measured and this value was subtracted from the $A_{532}$ to eliminate the interferences of soluble sugars in the samples. All values were referred to fresh weight.

\subsection{NO end-products determination}

To estimate NO generation, NO oxidation end-products (nitrate and nitrite) were measured in the soluble fraction of the Ramalina farinacea thalli using a Skalar autoanalyzer, model SAN ++ . The automated determination of nitrate and nitrite is based on the cadmium reduction method: the sample is passed through a column containing granulated copper-cadmium to reduce nitrate to nitrite. The nitrite (that originally present plus that obtained from the reduction of nitrate) concentration is determined by its diazotization with sulfanilamide followed by coupling with $\mathrm{N}-(1-$ naphthyl)ethylenediamine dihydrochloride to form a highly coloured azo dye, the absorbance of which is measured at $540 \mathrm{~nm}$. This is the most commonly used method to analyse NO production and is known as the Griess reaction (Nagano, 1999).

\subsection{Statistics}

At least three samples for each treatment and each incubation time were prepared. Four assays were carried out on four different days for the lichens and on three different days for the algae. Data were analysed for significance with Student's $t$-test or by ANOVA.

\section{Results}

\subsection{Chlorophyll autofluorescence, ROS generation, lipid peroxidation and NO production in whole thalli}

The presence of $\mathrm{CP}$ in water during rehydration provokes a delayed recuperation of chlorophyll autofluorescence (Fig. 1A) and slight reduction in the levels of free radicals (Fig. 1C) during the first hour post-hydration.

The confocal study reveals that rehydration induces free radical production especially by phycobionts (Fig. $2 \mathrm{~A}$, detail $\mathrm{A}_{1}$ ). Hyphae show also intracellular production of free radicals, especially in the condroid area and the cortex (Fig. 2A). Close-up examination reveals that phycobiont free radical production is linked to the

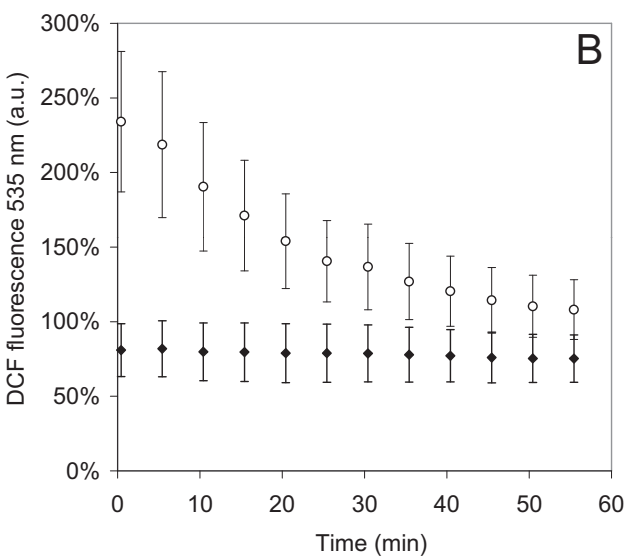

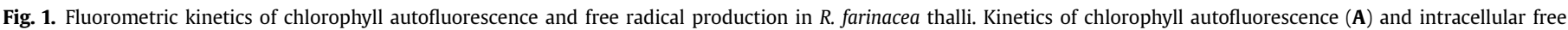

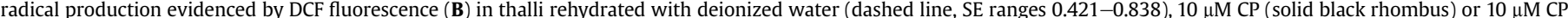

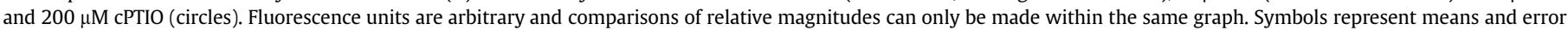
bars (SE) of 12 replicates. 



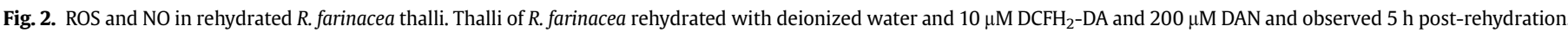



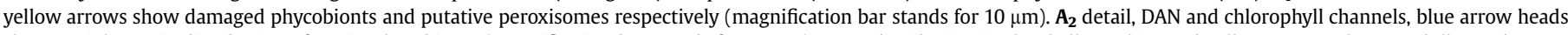

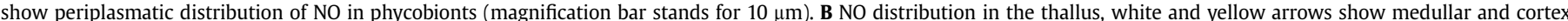





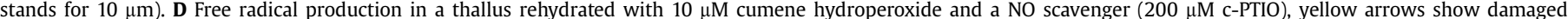

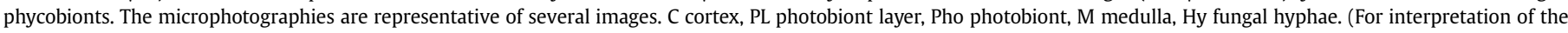
references to colour in this figure legend, the reader is referred to the web version of this article.)

chloroplast reflecting its morphology in an especially accurate way (Fig. $2 \mathrm{~A}_{1}, \mathrm{~A}_{2}$ ). Free radical rich vesicles, putative peroxisomes, can be seen in some phycobionts (Fig. $2 \mathrm{~A}_{1}$ ). $\mathrm{NO}$ is detected in the cytoplasm of mycobionts, both in medullar and peripheral hyphae. Phycobionts' NO is located mainly in a thin peripheral area around the chloroplast, perhaps associated to cell membrane (Fig. 2A2, B). Damaged phycobionts show elevated levels of free radicals and NO and a reduction of chlorophyll autofluorescence (Fig. 2A, B). CP induces an apparent reduction of NO levels, especially in the medulla, and in phycobionts that lose peripheral NO and an increase in free radicals production (Fig. 2C).

NO-endproducts $\left(\mathrm{NO}_{x}\right)$ quantification serves as an estimation of NO production. $\mathrm{CP}$ induces a dramatic increase in $\mathrm{NO}_{x} 2 \mathrm{~h}$ after rehydration, dropping then below control levels at $4 \mathrm{~h}$ but recovering at $24 \mathrm{~h}$ (Fig. 3A). Lipid peroxidation (TBARS) is significantly increased by $\mathrm{CP}$ during the first $1 \mathrm{~h}$, but then there is a dramatic decrease near to $50 \%$ of controls at $4 \mathrm{~h}$ (Fig. 3B). At longer times $(24 \mathrm{~h})$, values increase above $150 \%$.

NO inhibition during CP treatment (Fig. 1) stimulates chlorophyll autofluorescence above control levels and launches free radical production over $200 \%$ above controls in the first minutes. Both are contrary effects to $\mathrm{CP}$ alone. Free radical values descend rapidly and are similar to controls after $50 \mathrm{~min}$. Confocal images seem to confirm an increase in free radical production especially in phycobionts (Fig. 2C). CP induced chlorophyll autoflorescence inhibition is even stronger in hydrated lichens, 60-70\% (Fig. 4). NO-inhibition in these conditions leads to a faster recovery of control levels.

The inhibition of NO effects during CP treatment causes an increase in free radical production by phycobionts (Fig. 2D) and decrease in $\mathrm{NO}_{x}$, whose levels are lower referred to $\mathrm{CP}$ alone and even controls (Fig. 3A). Lipid peroxidation values also differ significantly from CP alone and are similar or slightly lower than controls (Fig. 3B). In isolated phycobionts this treatment only induces a slight increase which is not significant (Table 1).

\subsection{Studies on isolated algae}

\subsubsection{Microscopical studies}

In order to compare the effects that $\mathrm{CP}$ produced on isolated phycobionts with lichen thalli we incubated Trebouxia sp. 

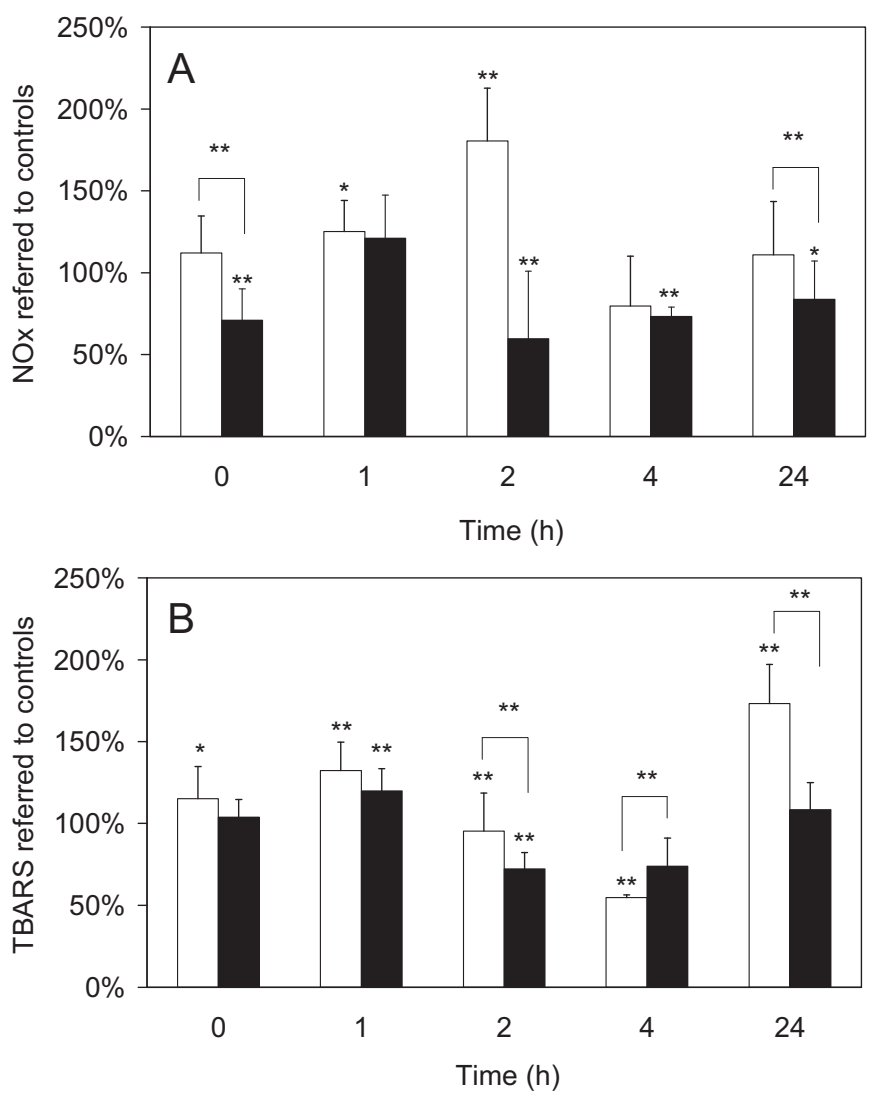

Fig. 3. TBARS and NO end-products of rehydrated Ramalina farinacea thalli. White bars correspond to rehydration with $10 \mu \mathrm{M} \mathrm{CP}$, black bars to rehydration with $10 \mu \mathrm{M} \mathrm{CP}$ plus $200 \mu \mathrm{M}$ c-PTIO. A NO end-products. B TBARS content referred to controls. Student $t$ test: ${ }^{*} p<0.05,{ }^{* *} p<0.01$. The error bars represent the SE of at least 9 replicates.

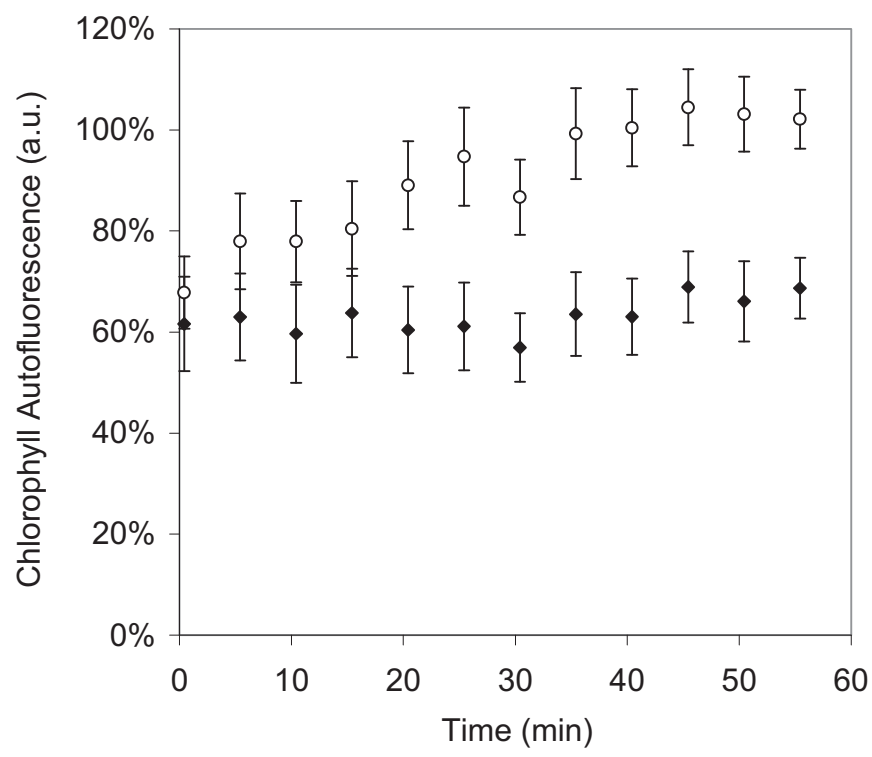

Fig. 4. Chlorophyll autofluorescence in hydrated Ramalina farinacea. Kinetics of chlorophyll autofluorescence in hydrated thalli treated with $10 \mu \mathrm{M}$ CP (solid black rhombus) or $10 \mu \mathrm{M}$ CP plus $200 \mu \mathrm{M}$ CPTIO (circles) for 5 min referred to controls treated with deionized water. Fluorescence units are arbitrary and comparisons of relative magnitudes can only be made within the same graph. Symbols represent means and error bars of 12 replicates.
Table 1

TBARS (nEq TEP $/ 10^{6}$ cells) of Ramalina farinacea isolated phycobionts at different time points after the establishment of the algal suspension $(n=12)$.

\begin{tabular}{llll}
\hline Time $(\mathrm{h})$ & Control & $10 \mu \mathrm{M} \mathrm{CP}$ & $10 \mu \mathrm{M} \mathrm{CP}+200 \mu \mathrm{M} \mathrm{c}-\mathrm{PTIO}$ \\
\hline 0 & $1.6 \pm 0.3$ & $2.0 \pm 0.2$ & $1.8 \pm 0.2$ \\
1 & $1.5 \pm 0.2$ & $1.6 \pm 0.2$ & $1.7 \pm 0.2$ \\
2 & $2.8 \pm 0.6$ & $2.8 \pm 0.7$ & $4.6 \pm 1.3$ \\
4 & $1.4 \pm 0.2$ & $1.8 \pm 0.3$ & $1.2 \pm 0.2$ \\
24 & $1.3 \pm 0.1$ & $1.4 \pm 0.1$ & $1.4 \pm 0.7$ \\
\hline
\end{tabular}

suspensions with $10 \mu \mathrm{M} \mathrm{CP}$ and both epifluorescence probes. No difference was observed between control (Fig. 5a) and CP treated photobionts (data not shown). The inhibition of NO resulted in a visible increase of free radicals, especially in the periphery of the cells, and dimmed chlorophyll autofluorescence (Fig. 5b).

The production of TBARS by CP was also studied in Trebouxia sp. phycobionts in suspension. TBARS do not undergo significant variations after $\mathrm{CP}$ or $\mathrm{CP}+\mathrm{cPTIO}$ treatment (Table 1 ).

\subsubsection{Photosynthetic activity}

We also performed in vitro experiments with $A$. erici axenic cultures in order to confirm whether the visualized behaviour of the fluorescent probes after the photooxidative stress was linked to alterations in the photosynthetic activity. Algal cells were cultured on cellulose discs, desiccated during $24 \mathrm{~h}$ and rehydrated with water, $\mathrm{CP}$ or/and c-PTIO. The addition of the oxidizing agent $\mathrm{CP}$ did not alter the photosynthetic activity after rehydration (Table 2). However, the scavenging of NO by CPTIO increased the photoinhibition of the PSII denoted by a significant decrease of the maximum efficiency of the Photosystem II $\left(F_{v} / F_{m}\right)$ and its relative efficiency ( $\Phi_{\text {PSII }}$ ). The simultaneous exposition to CP and c-PTIO had a synergic negative effect on photosynthesis; $F_{v} / F_{m}$ and $\Phi_{\text {PSII }}$ values were around a $60 \%$ lower than upon a water rehydration. The oxidation degree of the Quinone $\mathrm{A}\left(\mathrm{Q}_{\mathrm{A}}\right)$, determined by $q_{\mathrm{P}}$, depends on the activation state of the Photosystem I (PSI) and the Calvin
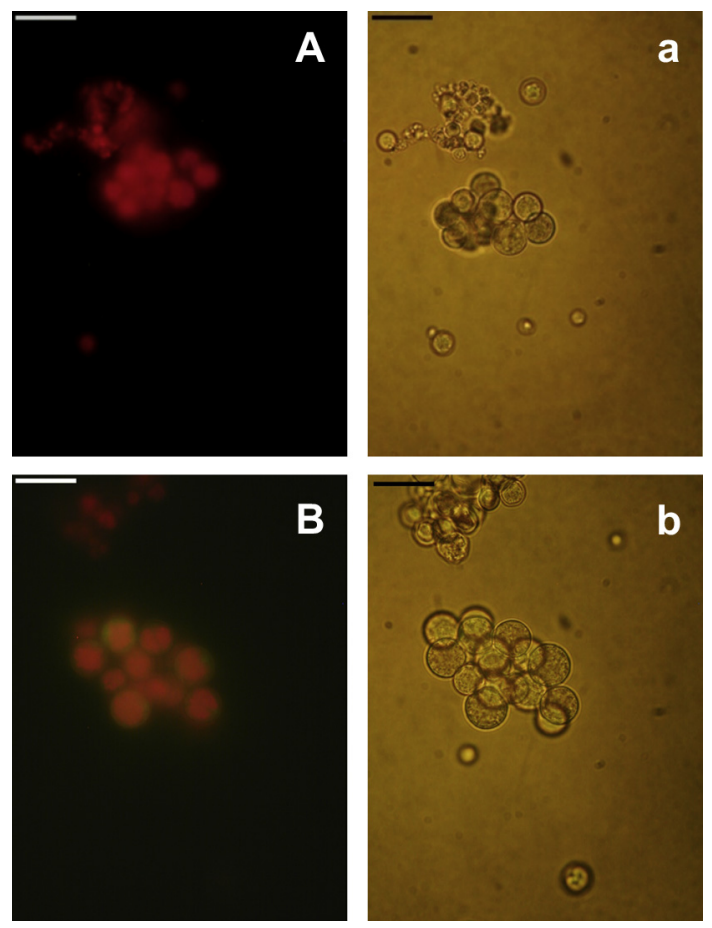

Fig. 5. ROS content of isolated Trebouxia sp. Capital letters identify the fluorescence image, the lower case indicates the corresponding bright field images: A-a $10 \mu \mathrm{M} \mathrm{CP}$ treated phycobionts; B-b $10 \mu \mathrm{M}$ CP plus $200 \mu \mathrm{M}$ c-PTIO treated phycobionts. 
Table 2

Photosynthetic parameters of axenic cultures of Asterochloris erici desiccated for $24 \mathrm{~h}$ and then rehydrated with deionized water, $10 \mu \mathrm{M} \mathrm{CP}$ or $10 \mu \mathrm{M} \mathrm{CP}$ plus $200 \mu \mathrm{M} \mathrm{c}$ PTIO. The algae were incubated under normal culture conditions for $24 \mathrm{~h}$ before chlorophyll $a$ fluorescence was measured. Control algae were not desiccated but instead maintained under normal culture conditions. $F_{\mathrm{v}} / F_{\mathrm{m}}$, maximum photochemical efficiency of photosystem II (PSII); $\Phi_{\text {PSII }}$, photochemical efficiency in light: $q_{\mathrm{P}}$, photochemical component of fluorescence relaxation. Different letters show significant differences between treatments. LSD test $(p<0.05), n=3$.

\begin{tabular}{llll}
\hline Treatment & $F_{\mathrm{v}} / F_{\mathrm{m}}$ & $\Phi_{\text {PSII }}$ & $q_{\mathrm{P}}$ \\
\hline Control & $0.625 \pm 0.023^{\mathrm{a}}$ & $0.518 \pm 0.008^{\mathrm{a}}$ & $0.881 \pm 0.007^{\mathrm{a}}$ \\
$\mathrm{H}_{2} \mathrm{O}$ & $0.246 \pm 0.060^{\mathrm{b}}$ & $0.116 \pm 0.027^{\mathrm{b}}$ & $0.650 \pm 0.040^{\mathrm{a}}$ \\
$10 \mu \mathrm{M} \mathrm{CP}$ & $0.229 \pm 0.022^{\mathrm{b}}$ & $0.118 \pm 0.049^{\mathrm{b}}$ & $0.673 \pm 0.142^{\mathrm{a}}$ \\
$10 \mu \mathrm{M} \mathrm{CP}+200 \mu \mathrm{M} \mathrm{c-PTIO}$ & $0.112 \pm 0.036^{\mathrm{c}}$ & $0.049 \pm 0.018^{\mathrm{c}}$ & $0.596 \pm 0.136^{\mathrm{a}}$ \\
\hline
\end{tabular}

cycle (Maxwell et al., 1994). After the dehydration-rehydration treatments $q_{\mathrm{P}}$ remained unaltered indicating that photoinhibition was produced before $Q_{A}$ in the photosynthetic electron transport chain. The same treatments and measurements were carried out in whole thalli of $R$. farinacea but no alterations in photosynthesis at $24 \mathrm{~h}$ were observed (data not shown).

\section{Discussion}

Our results demonstrate the lichen thallus of Ramalina farinacea to be a complex system. ROS production must not be identified with oxidative stress since this will depend on the balance between prooxidants and antioxidants available within the system. Only an imbalance between the two will result in oxidative damage. Instead, lipid peroxidation, measured as MDA, has long been used to characterize oxidative damage in cells and was the approach used in this study. On the other hand, living organisms modulate their response along time; it has been shown that an initial damage can activate the cellular compensatory mechanisms resulting later in an apparent opposite response. This compensatory effect is known as hormesis (Calabrese and Blain, 2009) and seems to be present in lichens. NO has been shown to be involved in abiotic stress responses (Neill et al., 2008) and plant defence (Hong et al., 2008) and is now demonstrated to participate in lichen biology. Furthermore, it is a universal signalling molecule produced by both myco- and phycobionts whose half-life may allow it to travel from one cell type to another.

The lack of effect of CP on early intracellular ROS indicates that $R$. farinacea possesses potent antioxidant systems able to compensate for CP pro-oxidant effects during the initial moments of rehydration as well as in hydrated thalli, probably a compensatory effect known as hormesis. Despite this, confocal images show an increase of ROS in the medullar cellular bodies and especially in chloroplasts. Besides, CP induces lipid peroxidation $(24 \mathrm{~h})$ that could indicate a depletion of antioxidant reserves which are compromised by rehydration itself (Catalá et al., 2010b; Weissman et al., 2005). Lipid peroxidation can induce alterations on membrane function (nutrient transport, osmotic regulation, cell communication or cell wall synthesis and repair). Alterations in mitochondrial and chloroplast membranes could affect electron chains for ATP production or photosynthesis. Despite the low dose of $\mathrm{CP}$ used in this work $(10 \mu \mathrm{M})$ did not induce alterations in photosynthesis, higher doses dramatically decreased photosynthesis in insolated R. Farinacea phycobionts (del Hoyo et al., 2011).

Plant cells are especially well equipped to deal with free radicals and lipid peroxidation. Specifically, $R$. farinacea trebouxioid phycobionts have been demonstrated to have excellent antioxidant defences and tolerate micromolar doses of CP (del Hoyo et al., 2011; Álvarez et al., 2012). However, fungal metabolism of CP can produce cytotoxic intracellular oxidative damage and even cell necrosis
(Persoon-Rothert et al., 1992). Our results regarding phycobiont lipid peroxidation support that algal membranes are better suited to avoid this effect. A specific approach should be designed to clarify whether lichen mycobiont's peroxidation levels are higher than phycobiont's under PC stress.

Early $\mathrm{NO}_{x}$ increase indicates that the lichen releases larger quantities of $\mathrm{NO}$ in response to $\mathrm{CP}$. Confocal imaging shows that $\mathrm{CP}$ also induces a change in the pattern of NO distribution. This suggests that NO release is differently regulated in each symbiont. Plant peroxisomes have been demonstrated to release NO (Corpas et al., 2009), however we have found no evidence of NO production in the structures we have termed "putative peroxisomes". Further studies are necessary to confirm their nature and function. NO inhibition causes dramatic changes during CP treatment cancelling its hormetic effect and allowing intracellular ROS levels to launch over control levels. The confocal images presented show that chloroplasts are still a major source of free radicals, although a previous study also revealed a ROS burst in mycobionts (Catalá et al., 2010a). In spite of this initial effect, NO inhibition prevents the increase of thalli lipid peroxidation after $24 \mathrm{~h}$ confirming an important role of this molecule in the regulation of lichen oxidative stress. These results regarding NO inhibition seem to be contradictory; it initially increases intracellular ROS production but later reduces lipid peroxidation. A possible explanation could be found on the likely different functions played by NO in myco and phycobionts since the effects of NO can be finely regulated by the presence of other reactants and the ambient redox status (Kroncke et al., 1997; Darley-Usmar et al., 2000).

Whereas CP caused a reduction of chlorophyll autofluorescence, simultaneous NO inhibition causes a reversion to control levels in hydrated thalli and an increase during the first minutes of rehydration of desiccated thalli. This combined treatment does not affect $R$. farinacea photosynthesis $24 \mathrm{~h}$ after rehydration but induces a strong decrease of photosynthetic parameters in cultured phycobionts. NO inhibition per se was shown to induce a moderate reduction in photosynthetic parameters in rehydrated $A$. erici (Catalá et al., 2010b) but CP exposure strongly enhances this effect. This complexity of NO regulation also appeared in former observations of Trebouxia photobionts where simple NO deprivation lead to a ROS burst and photobleaching but the combined treatment induced a moderate ROS increase (Catalá et al., 2010b). NO has been demonstrated to directly stabilize the chlorophyll molecule in plants (Wodala et al., 2008) and our previous data point to a similar role in trebouxioid photobionts (Catalá et al., 2010b). The data presented here support this hypothesis and demonstrate that the production of adequate levels of NO is important for photosynthesis in the presence of $\mathrm{CP}$. They also suggest that the early induction of hormetic compensatory mechanisms by $\mathrm{CP}$ can help prevent the damages caused by NO inhibition in chloroplasts. The maintenance of the pro-oxidant effects of $\mathrm{CP}$ along time could deplete antioxidants leading to the failure in photosynthesis observed after $24 \mathrm{~h}$.

Lichen's lack of dermal structures allows the entry of all the substances carried by water during rehydration cycles, including soluble volatile pollutants that could interfere with the highly reactive NO molecule. Given that NO regulates $R$. farinacea compensatory hormetic response to $\mathrm{CP}$, NO inactivation could be devastating in polluted environments. $\mathrm{CP}$ pro-oxidant effects could lead to photosynthesis alterations, depletion of antioxidant resources and an increase of lichen sensitivity to abiotic or biotic stress. Polluted environments usually present a complex mixture of air pollutants, the combined effects of $\mathrm{CP}$ and others such as ozone, nitrogen or sulphur oxides could be especially deleterious.

On the other hand, the dependence of trebouxioid photobionts on mycobiont-derived NO to maintain photosynthetic activity in 
the presence of environmental pro-oxidants could be part of the lichen symbiosis adaptive advantages. Kranner et al. (2005) reported an effective communication between mycobionts and photobionts, in which one partner up-regulates the antioxidant system of the other. As a matter of fact, an important role for NO in both in mycorhizic and legume-Rhizobium symbiosis has been proposed (Bonfante and Requena, 2011; Meilhoc et al., 2011; Hérouart et al., 2002). Although NO is short lived, it can easily traverse cell membranes and act in a point relatively distant to its origin, whether directly or activating signal transduction cascades (Courtois et al., 2008; Wilson et al., 2008). Specifically designed assays should be performed to confirm such a role for NO in lichen symbiosis.

\section{Conclusions}

Overall, our results suggest that the pro-oxidant organic pollutant CP induces a compensatory hormetic response in Ramalina farinacea that could reduce and even deplete the lichen's antioxidant resources after repeated desiccation-rehydration cycles. NO plays an important role in the protection from CP although its effects in each symbiont may be quite different. NO seems to be released by mycobionts to protect the photosynthetic complex from $\mathrm{CP}$ at the cost of inducing lipid peroxidation.

\section{Authors contributions}

EB and MC conceived Objectives and designed the study and general design of the work. FG and EB collected and identified $R$. farinacea thalli. Microscopy and image handling were performed by FG-B and J R-A. FG designed and carried out photobionts isolation and physiology of photosynthesis experiments. Studies on lipid peroxidation and NO-endproducts quantification were made by AEP. MC and FG wrote the paper and EB made final considerations. All authors read and approved the final manuscript.

\section{Acknowledgements}

This project was funded by the Spanish Ministry of Education and Science [project numbers CGL2012-40058-C02-01 and CGL2009-13429-C02-01], project Prometeo 2008/174 of the Generalitat Valenciana and the project AECID PCI/A/024755/09 of the Spanish Ministry of Foreign Affaires.

\section{Abbreviations}

\begin{tabular}{|c|c|}
\hline u. & arbitrary units \\
\hline BHT & 2,6-di-tert-buthyl-4-methylphenol \\
\hline $\mathrm{CP}$ & cumene hydroperoxide \\
\hline \multicolumn{2}{|c|}{$\begin{aligned} \text { c-PTIO, carboxy-PTIO } & \text { 2-(4-carboxyphenyl)-4,4,5,5- } \\
& \text { tetramethylimidazoline-1-oxyl-3-oxide, } \\
& \text { potassium salt }\end{aligned}$} \\
\hline DAF-DA & $\begin{array}{l}\text { 4- amino- 5- methylamino- } 2^{\prime}, 7^{\prime} \text { - difluorofluorescein } \\
\text { diacetate }\end{array}$ \\
\hline DAN & 2,3-diaminonaphthalene \\
\hline DCF & $2^{\prime}, 7^{\prime}$ - dichlorofluorescin \\
\hline $\mathrm{DCFH}_{2}$ & $2^{\prime}, 7^{\prime}$ - dichlorodihydrofluorescein \\
\hline \multicolumn{2}{|c|}{$\mathrm{DCFH}_{2}$-DA $2^{\prime}, 7^{\prime}$ - dichlorodihydrofluorescein diacetate } \\
\hline MDA & malondialdehyde \\
\hline NAT & 1-H-naphthotriazole \\
\hline ROS & reactive oxygen species \\
\hline SE & standard error \\
\hline TBARS & thiobarbituric acid reactive substances \\
\hline EP & ,2,2-tetraethoxypropane \\
\hline
\end{tabular}

\section{Appendix A. Supplementary data}

Supplementary data related to this article can be found at http:// dx.doi.org/10.1016/j.envpol.2013.04.015.

\section{References}

Álvarez, R., Del Hoyo, A., Garcia-Breijo, F., Reig-Arminana, J., Del Campo, E.M., Guera, A., Barreno, E., Casano, L.M., 2012. Different strategies to achieve Pbtolerance by the two Trebouxia algae coexisting in the lichen Ramalina farinacea. Journal of Plant Physiology 169, 1797-1806.

Arasimowicz, M., Floryszak-Wieczorek, J., 2007. Nitric oxide as a bioactive signaling molecule in plant stress responses. Plant Science 172, 876-887.

Augusto, S., Maguas, C., Matos, J., Pereira, M.J., Branquinho, C., 2010. Lichens as an integrating tool for monitoring PAH atmospheric deposition: a comparison with soil, air and pine needles. Environmental Pollution 158, 483-489.

Bačkor, M., Fahselt, D., 2003. Effects of acidity on some physiological parameters of laboratory re-synthesized lichen Cladonia cristatella and its isolated mycobiont. Bryologist 106, 583-587.

Bačkor, M., Váczi, P., 2002. Copper tolerance in the lichen photobiont Trebouxia erici (chlorophyta). Environmental and Experimental Botany 48, 11-20.

Bačkor, M., Kovacik, J., Piovar, J., Pisani, T., Loppi, S., 2010. Physiological aspects of cadmium and nickel toxicity in the lichens Peltigera rufescens and Cladina arbuscula Subsp mitis. Water Air and Soil Pollution 207, 253-262.

Bačkor, M., Péli, E.R., Vantová, I., 2011. Copper tolerance in the macrolichens Cladonia furcata and Cladina arbuscula subsp. mitis is constitutive rather than inducible. Chemosphere 85, 106-113.

Bajpai, R., Upreti, D.K., 2012. Accumulation and toxic effect of arsenic and other heavy metals in a contaminated area of West Bengal, India, in the lichen Pyxine cocoes (Sw.) Nyl. Ecotoxicology and Environmental Safety 83, 63-70.

Barr, D.P., Martin, M.V., Guengerich, F.P., Mason, R.P., 1996. Reaction of cytochrome P450 with cumene hydroperoxide: ESR spin-trapping evidence for the homolytic scission of the peroxide $\mathrm{O}-\mathrm{O}$ bond by ferric cytochrome P450 1A2. Chemical Research in Toxicology 9, 318-325.

Barreno, E., 2002. Leader "Expresion of Interest" UE: 2002-2006. In: Acronym: MOEBIOS. "Monitoring the Effects of Global Environmental Change on the Biodiversity of Sensitive Organisms". http://eoi.cordis.lu/search_form.cfm. Towards a Network of Excellence on the Significance for Europe Biomonitoring Global Environmental Change. TP 1.6. Sustainable Development, Global Change and Ecosystems.

Bonfante, P., Requena, N., 2011. Dating in the dark: how roots respond to fungal signals to establish arbuscular mycorrhizal symbiosis. Current Opinion in Plant Biology 14, 451-457.

Botsoglou, N.A., Fletouris, D.J., Papageorgiou, G.E., Vassilopoulus, V.N., Mantis, A.J., Trakatellis, A.G., 1994. Rapid, sensitive, and specific thiobarbituric acid method for measuring lipid-peroxidation in animal tissue, food, and feedstuff samples. Journal of Agricultural and Food Chemistry 42, 1931-1937.

Calabrese, E.J., Blain, R.B., 2009. Hormesis and plant biology. Environmental Pollution $157,42-48$.

Callen, D.F., Larson, R.A., 1978. Toxic and genetic effects of fuel oil photoproducts and three hydroperoxides in Saccharomyces cerevisiae. Journal of Toxicology and Environmental Health 4, 913-917.

Catalá, M., Gasulla, F., Pradas del Real, Ana E., Garcia-Breijo, F.J., Reig-Arminana, J., Barreno, E., 2010a. In: Nash III, T., Geiser, L., McCune, B., Triebel, D., Tomescu, A.M., Sanders, W. (Eds.), Nitric Oxide is Involved in Oxidative Stress During Rehydration of Ramalina farinacea (L.) Ach. in the Presence of the Oxidative Air Pollutant Cumene Hydroperoxide. E. Schweizerbart Science Publishers, Stuttgart, p. 256.

Catalá, M., Gasulla, F., Pradas, D.R., Garcia-Breijo, F., Reig-Arminana, J., Barreno, E., 2010b. Fungal-associated NO is involved in the regulation of oxidative stress during rehydration in lichen symbiosis. BMC Microbiology 10, 297.

Corpas, F.J., Hayashi, M., Mano, S., Nishimura, M., Barroso, J.B., 2009. Plant Physiology 151, 2083-2094.

Corpas, J.F., Barroso, J.B., Carreras, A., Valderrama, R., Palma, J.M., del Río, L.A., 2006. Nitrosative stress in plants: a new approach to understand the role of NO in abiotic stress. In: Lamattina, L., Polacco, J.C. (Eds.), Nitric Oxide in Plant Growth. Springer-Verlag, Berlin Heidelberg, pp. 187-205.

Corpas, J.F., Leterrier, M., Valderrama, R., Airaki, M., Chaki, M., Palma, J.M., Barroso, J.B., 2011. Nitric oxide imbalance provokes a nitrosative response in plants under abiotic stress. Plant Science 181, 604-611.

Courtois, C., Besson, A., Dahan, J., Bourque, S., Dobrowolska, G., Pugin, A., Wendehenne, D., 2008. Nitric oxide signalling in plants: interplays with $\mathrm{Ca}^{2+}$ and protein kinases. Journal of Experimental Botany 59, 155-163.

Darley-Usmar, V.M., Pate, R.P., O’Donnell, V.B., Freeman, B.A., 2000. In: Ignarro, L. (Ed.), Antioxidant Actions of Nitric Oxide. Academic Press, Los Ángeles, pp. 265-276.

Du, Z.Y., Bramlage, W.J., 1992. Modified thiobarbituric acid assay for measuring lipid oxidation in sugar-rich plant-tissue extracts. Journal of Agricultural and Food Chemistry 40, 1566-1570.

del Hoyo, A., Álvarez, R., del Campo, E.M., Gasulla, F., Barreno, E., Casano, L.M., 2011. Oxidative stress induces distinct physiological responses in the two Trebouxia phycobionts of the lichen Ramalina farinacea. Annals of Botany 107, 109-118.

Feelisch, M., Martin, J.F., 1995. The early role of nitric oxide in evolution. Trends in Ecology \& Evolution 10, 496-499. 
Garty, J., Tomer, S., Levin, T., Lehr, H., 2003. Lichens as biomonitors around a coalfired power station in Israel. Environmental Research 91, 186-198.

Gasulla, F., Guéra, A., Barreno, E., 2010. A simple and rapid method for isolating lichen photobionts. Symbiosis 51, 175-179.

Gasulla, F., Gómez de Nova, P., Esteban-Carrasco, A., Zapata, J.M., Barreno, E., Guéra, A., 2009. Dehydration rate and time of desiccation affect recovery of the lichenic algae Trebouxia erici: alternative and classical protective mechanisms. Planta 231, 195-208.

Genty, B., Briantais, J.M., Baker, N.R., 1989. The relationship between the quantum yield of photosynthetic electron-transport and quenching of chlorophyll fluorescence. Biochimica et Biophysica Acta (BBA) 990, 87-92.

Goldsmith, S.J., Thomas, M.A., Gries, C., 1997. A new technique for photobiont culturing and manipulation. The Lichenologist 29, 559-569.

Haslekås, C., Viken, M.K., Grini, P.E., Nygaard, V., Nordgard, S.H., Meza, T.J., Aalen, R.B., 2003. Seed 1-cysteine peroxiredoxin antioxidants are not involved in dormancy, but contribute to inhibition of germination during stress. Plant Physiology 133, 1148-1157.

Hauck, M., 2010. Ammonium and nitrate tolerance in lichens. Environmental Pollution 158, 1127-1133.

Hauck, M., Juergens, S., Brinkmann, M., Herminghaus, S., 2008. Surface hydrophobicity causes $\mathrm{SO}_{2}$ tolerance in lichens. Annals of Botany 101, 531-539.

Hérouart, D., Baudouin, E., Frendo, P., Harrison, J., Santos, R., Jamet, A., Van de Sype, G., Touati, D., Puppo, A., 2002. Reactive oxygen species, nitric oxide and glutathione: a key role in the establishment of the legume-Rhizobium symbiosis? Plant Physiology and Biochemistry 40, 619-624.

Hong, J.K., Yun, B., Kang, J., Raja, M.U., Kwon, E., Sorhagen, K., Chu, C., Wang, Y., Loake, G.J., 2008. Nitric oxide function and signalling in plant disease resistance. Journal of Experimental Botany 59, 147-154.

Horneck, G., Klaus, D.M., Mancinelli, R.L., 2010. Space microbiology. Microbiology and Molecular Biology Reviews 74, 121-156.

Kojima, H., Sakurai, K., Kikuchi, K., Kawahara, S., Kirino, Y., Nagoshi, H., Hirata, Y., Akaike, T., Maeda, H., Nagano, T., 1997. Development of a fluorescent indicator for the bioimaging of nitric oxide. Biological and Pharmaceutical Bulletin 20, $1229-1232$.

Kong, F., Hu, W., Sang, W., Wang, L., 2002. Effects of sulphur dioxide on the relationship between symbionts in lichen. Ying Yong Sheng Tai Xue Bao 13, 151-155.

Kong, F.X., Hu, W., Chao, S.Y., Sang, W.L., Wang, L.S., 1999. Physiological responses of the lichen Xanthoparmelia mexicana to oxidative stress of $\mathrm{SO}_{2}$. Environmental and Experimental Botany 42, 201-209.

Kramer, D.M., Johnson, G., Kiirats, O., Edwards, G.E., 2004. New fluorescence parameters for the determination of $\mathrm{q}(\mathrm{a})$ redox state and excitation energy fluxes. Photosynthesis Research 79, 209-218.

Kranner, I., Birtic, S., 2005. A modulating role for antioxidants in desiccation tolerance. Integrative and Comparative Biology 45, 734-740.

Kranner, I., Cram, W.J., Zorn, M., Wornik, S., Yoshimura, I., Stabentheiner, E., Pfeifhofer, H.W., 2005. Antioxidants and photoprotection in a lichen as compared with its isolated symbiotic partners. Proceedings of the National Academy of Sciences of the United States of America 102, 3141-3146.

Kranner, I., 2002. Glutathione status correlates with different degrees of desiccation tolerance in three lichens. New Phytologist 154, 451-460.

Kranner, I., Beckett, R., Hochman, A., Nash III, T.H., 2008. Desiccation-tolerance in lichens: a review. Bryologist 111, 576-593.

Kroncke, K.D., Fehsel, K., Kolb-Bachofen, V., 1997. Nitric oxide: cytotoxicity versus cytoprotection- how, why, when, and where? Nitric Oxide-Biology and Chemistry 1, 107-120.

Kumar, J.S., Suman, S., Singh, V., Chandna, S., 2012. Radioresistant Sf9 insect cells display moderate resistance against cumene hydroperoxide. Molecular and Cellular Biochemistry 367, 141-151.

Maxwell, C., Griffiths, H., Young, A.J., 1994. Photosynthetic acclimation to light regime and water stress by the $C_{3}$-CAM epiphyte Guzmania monostachia: gas exchange characteristics, photochemical efficiency and the xanthophyll cycle. Functional Ecology 8, 746-754.

Meilhoc, E., Boscari, A., Bruand, C., Puppo, A., Brouquisse, R., 2011. Nitric oxide in legume-rhizobium symbiosis. Plant Science 181, 573-581.
Nagano, T., 1999. Practical methods for detection of nitric oxide. Luminescence 14 283-290.

Nash, T.H., Gries, C., 2002. Lichens as bioindicators of sulfur dioxide. Symbiosis 33, $1-21$.

Nash, T.H., Gries, C., 1995. The use of lichens in atmospheric deposition studies with an emphasis on the Arctic. Science of the Total Environment 160-61, 737-747.

Neill, S., Barros, R., Bright, J., Desikan, R., Hancock, J., Harrison, J., Morris, P., Ribeiro, D., Wilson, I., 2008. Nitric oxide, stomatal closure, and abiotic stress. Journal of Experimental Botany 59, 165-176.

Oksanen, I., 2006. Ecological and biotechnological aspects of lichens. Applied Microbiology and Biotechnology 73, 723-734.

Pawlik-Skowronska, B., Backor, M., 2011. Zn/Pb-tolerant lichens with higher content of secondary metabolites produce less phytochelatins than specimens living in unpolluted habitats. Environmental and Experimental Botany 72, 64-70.

Persoon-Rothert, M., Egas-Kenniphaas, J.M., van der Valk-Kokshoorn, E.J., van der Laarse, A., 1992. Cumene hydroperoxide induced changes in calcium homeostasis in cultured neonatal rat heart cells. Cardiovascular Research 26, 706-712.

Riddell, J., Padgett, P.E., Nash III, T.H., 2012. Physiological responses of lichens to factorial fumigations with nitric acid and ozone. Environmental Pollution 170 202-210.

Reilly, C.A., Aust, S.D., 1999. Measurement of lipid peroxidation. In: Maines, M.D. Costa, L.C., Hodgson, E., Reed, D.J., Sipes, I.G. (Eds.), Current Protocols in Toxicology. John Wiley and Sons Inc., New York.

Riddell, J., Nash III, T.H., Padgett, P., 2008. The effect of $\mathrm{HNO}_{3}$ gas on the lichen Ramalina menziesii. Flora 203, 47-54.

Sen, S., Bhojnagarwala, P., Francey, L., Lu, D., Penning, T.M., Field, J., 2012. p53 mutagenesis by benzo[a]pyrene derived radical cations. Chemical Research in Toxicology 25, 2117-2126.

Siddiqui, M.H., Al-Whaibi, M.H., Basalah, M.O., 2011. Role of nitric oxide in tolerance of plants to abiotic stress. Protoplasma 248, 447-455.

State, G., Popescu, I.V., Radulescu, C., Macris, C., Stihi, C., Gheboianu, A., Dulama, I. Nitescu, O., 2012. Comparative studies of metal air pollution by atomic spectrometry techniques and biomonitoring with moss and lichens. Bulletin of Environmental Contamination and Toxicology 89, 580-586.

Tice, R., Brevard, B., 1998. Cumene Hydroperoxide [80-15-9]. Review of Toxicological Literature. Prepared for E. Zeigler of the. National Institute of Environmental Health Sciences, p. 64.

Timmins, G.S., Davies, M.J., 1993. Free radical formation in isolated murine keratinocytes treated with organic peroxides and its modulation by antioxidants Carcinogenesis 14, 1615-1620.

Tretiach, M., Piccotto, M., Baruffo, L., 2007. Effects of ambient $\mathrm{NO}_{x}$ on chlorophyll a fluorescence in transplanted Flavoparmelia caperata (Lichen). Environmental Science and Technology 41, 2978-2984.

Tsai, M.C., Chen, Y.H., Chiang, L.Y., 1997. Polyhydroxylated C60, fullerenol, a novel free-radical trapper, prevented hydrogen peroxide- and cumene hydroperoxide-elicited changes in rat hippocampus in-vitro. Journal of Pharmacy and Pharmacology 49, 438-445.

Victorin, K., Stahlberg, M., 1988. Photochemical formation of mutagenic compounds from alkenes and ozone or nitrogen dioxide. Environmental and Molecular Mutagenesis 11, 79-90.

Wannaz, E.D., Carreras, H.A., Rodriguez, J.H., Pignata, M.L., 2012. Use of biomonitors for the identification of heavy metals emission sources. Ecological Indicators 20, 163-169.

Wardman, P., 2007. Fluorescent and luminescent probes for measurement of oxidative and nitrosative species in cells and tissues: progress, pitfalls, and prospects. Free Radical Biology and Medicine 43, 995-1022.

Weissman, L., Garty, J., Hochman, A., 2005. Rehydration of the lichen Ramalina lacera results in production of reactive oxygen species and nitric oxide and a decrease in antioxidants. Applied and Environmental Microbiology 71 2121-2129.

Wilson, I.D., Neill, S.J., Hancock, J.T., 2008. Nitric oxide synthesis and signalling in plants. Plant, Cell \& Environment 31, 622-631.

Wodala, B., Deak, Z., Vass, I., Erdei, L., Altorjay, I., Horvath, F., 2008. In vivo target sites of nitric oxide in photosynthetic electron transport as studied by chlorophyll fluorescence in pea leaves. Plant Physiology 146, 1920-1927. 